Open Access

\title{
Studying the effect of institutional pressures on the intentions to continue green information technology usage
}

\author{
Abdul Aladheem Driafish Jabbar Alziady ${ }^{1 *}$ and Sabah H. Enayah ${ }^{2}$
}

\author{
* Correspondence: \\ Dr.abdaladheem@yahoo.com \\ 'Department of Business \\ Administration, College of \\ Economic and Administration, The \\ University of Thi-Qar, Nasiriyah, Iraq \\ Full list of author information is \\ available at the end of the article
}

\begin{abstract}
The last decade witnessed the emergence of green information technology(GIT) which includes organizational initiatives to reduce the negative impact of information technology (IT) on the environment. GIT has gained considerable interest among researchers because of a huge negative impact on the environment and an extensive use of information technology. A research instrument has been developed to link three components: coercive pressure, normative influence, and mimicry and stdy their effect on GIT adopt and continuance intentions. The model is validated using data collected from a field survey of 99 managers of small enterprises (SEs) in Thi-Qar province. The analysis that normative pressures are the most influential in the adoption of green IT. The coercive pressures have the most significant effect on the continuance usage of GIT practices. The current study would contribute to illustrate knowledge in the field of IT, regarding the decision maker's intention for the adoption and continue using GIT through the development of a theoretical framework that identified the key factors of GIT adoption and intention continuance.
\end{abstract}

Keywords: Green information technology, Institutional pressures

\section{Introduction}

Although the negative impact of IT, which mostly involves IT-related emissions and e-waste, has a concern among organizations, industries, and governments around the world during the last two decades, managers of Small enterprise (SEs) in Thi-Qar province, which is located in the south of Iraq, not interested. Recently, most of SEs focused on improving efficiency and enhancing environmental performance with reduced costs to improve environmental firm performance and respond to the increasing public awareness of environmental issues (Cai et al. 2013; Xia et al. 2014; HardinRamanan et al. 2018; Alzaidy 2018). Therefore, the managers of SEs have become enthusiastic about encouraging green information technology (GIT) initiatives and they have firmly stood behind their organizations to help it.

Consequently, GIT has been embraced by most of the SE's managers to reduce their ecological footprint and dispose of electronic waste environmentally to avoid the consequences of non-acceptance in the environment. As long as Managers' actions and behavior are vital to the GIT success within SEs, GIT effectiveness is greatly dependent on their intention to utilize IT resources. However, most of the prior studies on this

(c) The Author(s). 2019 Open Access This article is distributed under the terms of the Creative Commons Attribution 4.0 International License (http://creativecommons.org/licenses/by/4.0/), which permits unrestricted use, distribution, and reproduction in any medium provided you give appropriate credit to the original author(s) and the source, provide a link to the Creative Commons license, and indicate if changes were made. 
subject focused on factors influencing GIT adoption and usage from the organizational perspective (Chen et al. 2011; Gholami et al. 2013; Molla and Abareshi 2012; Molla et al. 2014). Consequently, there is a paucity of literature exploring the effects of institutional pressures on the intentions to continue using GIT, even though this information is vital for the managers of small businesses. Similarly, it would be beneficial to examine the role of institutional pressures in GIT adoption.

The reasons for GIT demonstration have recently attracted research attention. A number of researchers called for additional work that aimed to increase the understanding of the main reasons behind GIT adoption (Krell et al. 2016). In addition, scholars showed the limitation of GIT utilizing at SEs in Thi-Qar province attribute to lack of consistency understand the motivation behind GIT adoption (Alzaidy 2018). Subsequently, it is necessary to align the GIT practices and IT strategies of an enterprise which in turn necessary to understand GIT adoption, as this would eventually increase the success of this practice.

Therefore, the present study was guided by the following research questions: Do the institutional pressures influence the intentions of SE managers to continue GIT usage and what is the role of GIT adoption as a mediating variable between institutional pressures and SEs managers' intentions to continue GIT usage? Even though, GIT recently emerged as a vital research topic, according to some authors, there is a misconception that GIT practices cannot be an importance in developing countries such as Iraq. Due to this erroneous view, limited research on GIT adoption in this country presently exists. This gap in extant knowledge has motivated the present study as the author believe that this new field will be a great interest in the future because GIT offers opportunities for increasing economic, social and environmental returns. Krell et al. (2016), however, cautioned that mere adoption of GIT does not appear to be sufficient to diminish the detrimental effects of using IT. Most researchers concur that the SEs' continued GIT use governs the survival and flourishing of these practices (Chen et al. 2009; Coffey et al. 2013; Bohas and Poussing 2016). In other side and more importantly, literature has demonstrated that institutional pressures; including coercive pressure, normative influence, and mimicry that can influence the rate at which environmental practices are adopted. In addition, GIT diffused among firms (Lin et al., 2013). Following the aforementioned arguments, the major objectives of this work are:

(1) Exploring the influence of institutional pressures on SE managers' willingness in Thi-Qar province to adopt GIT practices.

(2) Determining the role of GIT adoption as a variable mediating the relationship between institutional pressures and intentions to continue GIT usage.

(3) Testing the relationships of the correlation and the effect of the variables of research.

\section{Literature review and hypothesis development}

The negative effect of technology on the natural environment in both local and global scales has attracted the attention of researchers, politicians, and activists. They have expressed worries about the environmental deterioration which has prompted the needs to understand the implications of technology on human safety, business, technology development, and environmental sustainability (Nishant et al. 2013). 
Therefore, GIT becomes a significant area of research in the information systems and environmental education (Hernandez 2017) and sustainability through GIT is increasingly considered an important strategic focus for organizations.

Consequently, GIT has sparked an intense debate on its ability to address these issues. Unfortunately, these are not new issues, since IT consumes resources in its production and in energy uses. ITs are generating e-waste once no longer in use (Khorasanizadeh et al. 2016). Recently, a new research field has emerged and aimed to increase the understanding of the relationships between investments in IT and its negative effect on the environment. While extant information systems literature provides important insights into GIT adoption, the motivation behind GIT adoption by small enterprises (SEs) remains unclear.

Gartner (2018) predicted that global IT expenditure in 2018 would reach \$3.7 trillion that represents $4.5 \%$ growth compared to 2017. Another author illustrated that the projected increase is due to energy consumption, $\mathrm{CO} 2$ emissions and e-waste (Murugesan 2008). If these issues are not addressed, IT contribution to global carbon emissions is anticipated to rise from $2 \%$ which is equivalent to the amount that has been generated by the aviation industry to as much as 6\% by 2020 (Hardin-Ramanan et al. 2018). Accordingly, there is an urgent needed to promote environmentally clean from IT usage (Xia et al. 2014). The growing accumulation of greenhouse gases (GHG) is claimed to cause changes in global climate with droughts in some areas and floods in others. There are pieces of evidence that Earth's temperature is steadily rising, generating severe and frequent weather related disasters (Murugesan and Gangadharan 2012).

IT produces a negative impact on the environment if we consider its lifecycle. Undoubted, GIT emerges as one of the organizational solutions that can be started to address this problem at the strategic and operational level. Jenkin et al. (2011) suggested that the objective of GIT is to reduce the overall environmental impact of information technology by using environment-friendly approaches throughout IT lifecycle. In a similar way, Bohas and Poussing in 2016 pointed that GIT practice leads to a reduction of the negative IT impacts on the environment as it is the main goal of GIT. Each year, the developed countries create more e-waste than developing countries. Nevertheless, the negative effect of e-waste is more complicated in developing countries since the cost of recycling e-waste in developed countries is ten times higher than in developing countries. It has known that most of the developed countries export e-waste to developing countries. This is a point of debate and controversy. Opponents of exporting e-waste to developing countries claim that it is a business. Other people feel that it is unfair. Furthermore, local people in the developing countries where they are not having enough experience and appropriate equipment, thus they burn or landfill e-waste which makes the problem aggravate. Over recent decades, IT manufacturers have been experiencing various pressures from a variety of stockholders which required them to make their products environmentally friendly. Therefore, they have been working to use raw materials that are not harmful to environment. In spite of, the fact that they invest huge money in order to reach their goal, the problem is getting worse. Until now, many countries in the Middle East have not taken any steps toward facing environmental issues. For this reason, we need to think carefully about e-waste.

However, some people feel that there are more urgent issues, our society is still facing a serious challenge resulting from e-waste. It may be true that governments have 
deferred plans to deal with this problem. When the computer stops working, owners either throws them out as wastes or keeps them at home. In both cases, there are serious dangers to public health. SEs are under pressures from customers, competitors, regulators, and society to implement GIT practices (Coffey et al. 2013). Hence, as a result, managers start thinking to evaluate the conditions for successful adoption and continued usage of GIT. GIT is an efficient resource consumption that utilizes IT infrastructure as well as deployment managerial, human practices, and organizational policies towards reducing the negative effect of IT (Molla et al. 2014). Numerous organizations have been recommended to have GIT on their agenda (Ardito and Morisio 2014), and fastened to their strategies (Hernandez and Ona 2016) to reach the full benefits of GIT.

There is still no mutual agreement on the precise of GIT definition (Jenkin et al. 2011). Many observers have pointed out that GIT is still in the early stages in the third world. Also, a large part of the ambiguity is attributed to the overlap between GIT and green information systems (GIS). Generally speaking, GIS indicates to improve and use of information systems (IS), such as groupware, teleconferencing, environment auditing systems, and automation systems that support and encourage environment-friendly operations and sustainable development (Cai et al. 2013; Sarkis et al. 2010; Watson et al. 2010). It supports and increases organizational activities for sustainable development and green innovation (Chen et al. 2008). Compared with (GIT) that essentially emphases on energy conservation related to computer use, GIS deals with wider-scope managerial concerns (Yang et al. 2018). Additionally, according to study was carried out by (Bohas and Poussing 2016) in 2016 which suggested that GIT attempt to have a direct effect by reducing the negative effect on the environment in the first place; then, it tends to have an indirect effect by using IS to encourage other business initiatives in reducing the negative environmental effect of IT. The present study will use the general term of GIT to include the two perspectives above since GIT is a new practice for the enterprises in Iraq and green information systems that are less developed yet. Recently, GIT is used to avoid the possibility of confusing the definition and to maintain congruence with practitioners who use this term (Thomson and van Belle 2015).

A number of definitions of GIT has emerged in literature. Greatest of these definitions are seeing IT environmental sustainability across the IT lifecycle. However, the most commonly cited definitions of GIT is provided by Murugesan and Gangadharan in 2012 who incorporates a wide variety of components of the ICT life cycle, such as design and manufacture with use and the disposal of ICT equipment: "the study and practice of designing, manufacturing, using, and disposing of computers, servers, and associated subsystems - such as monitors, printers, storage devices, and networking and communication systems-efficiently and effectively with minimal or no impact on the environment". Along similar lines (Moola et al. 2008) define Green IT "A systematic application of ecological-sustainability criteria (such as pollution prevention, product stewardship, use of clean technologies) to the design, production, sourcing, use and disposal of IT products and services in order to reduce IT, business process and supply chain related emissions, waste and water use, improve energy efficiency and generate tangible and intangible green economic rent". GIT refers to the design and implementation of information systems that support sustainable business processes (Chen et al. 2011). There is a more holistic definition which covers each of the areas within GIT 
and as a result of this, we decided to adopt it for this research. Decomposition of the aforementioned definitions revealed that it is a comprehensive approach to improve environmental sustainability which involves mitigating the negative effects of information technology on the environment throughout their life cycle and making environmentfriendly practices as a routine activity in the entire organization. Other researchers had described GIT as its products (e.g., software that manages an organization's overall emissions) and practices (e.g., disposal of IT equipment in an environmentally friendly way) which aimed to achieve pollution prevention, product stewardship, or sustainable development (Coffey et al. 2013). Correspondingly, this view was supported by (Molla et al. 2009) who stated that as an organization's ability to systematically apply sustainability criteria to design, produce, source, use and dispose of IT technical infrastructure as well as within the human and managerial components of IT. Based on the last definition, GIT can include technology aspects, as well as managerial practices spanning on IT lifecycle.

In sum, these definitions are intended to emphases that GIT is a lively initiative to encourage environmental consciousness to reduce the negative effects of information technology. A neuromas researchers are mostly agreed on basic definition to GIT that represent by which GIT is important of environmental damage reduction that mainly left behind by information technology used to the greatest extent possible.

The researchers stress the difficulty of defeating negative effect of IT in a decisive battle. Hence, the seed of coordination has blossomed to defeat a damage that caused by IT from the cradle to the grave. Consequently, the adoption motivation, as well as intentions to continue using green information technology which represents reasons for initiating a GIT that becomes the point of debate. Institutional perspective which is widely used in recent years to exam the justifications for the adoption of GIT that has traditionally focused on how organizations acquire institutional acceptance by complying to social expectations and dominant practices within the organizational field (DiMaggio and Powell 1983). Based on this view, values, and practices of GIT penetrates into organizations in the process of institutionalization which results in the convergence of organizational practices and responses (Oliver 1991; Tingling and Parent 2002). Accordingly, Institutional perspective proposed that organizations are seeking a balanced approach to economic growth which avoids them the devastation from the business that will be accepted by institutions in the firm's environment (Krell et al. 2016).

In this part of the research, we develop a research model derived from the institutional perspective(classical) that focuses on coercive pressures, normative influence and mimicry as institutional pressures affect continuing use of GIT practices. Our research model and constructs are shown in Fig. 1. In another way, we draw the pressures as motivations of organizations in adopting a GIT.

Institutional perspective explains drives which are molded as the independent variables in the research model would swift organizational behavior, which in turn may influence the success of that behavior (Krell et al. 2016). Drawing on our literature review, we have developed a research model to explicate the key determinants of GIT adoption. To avoid the potential confounding of normative pressures with mimetic and coercive pressures, some researchers address only mimetic and coercive pressures in the study of GIT adoption (Chen et al. 2009). In this study, we examine three types of institutional pressures to draw a holistic view. In our model, the Institutional pressures 


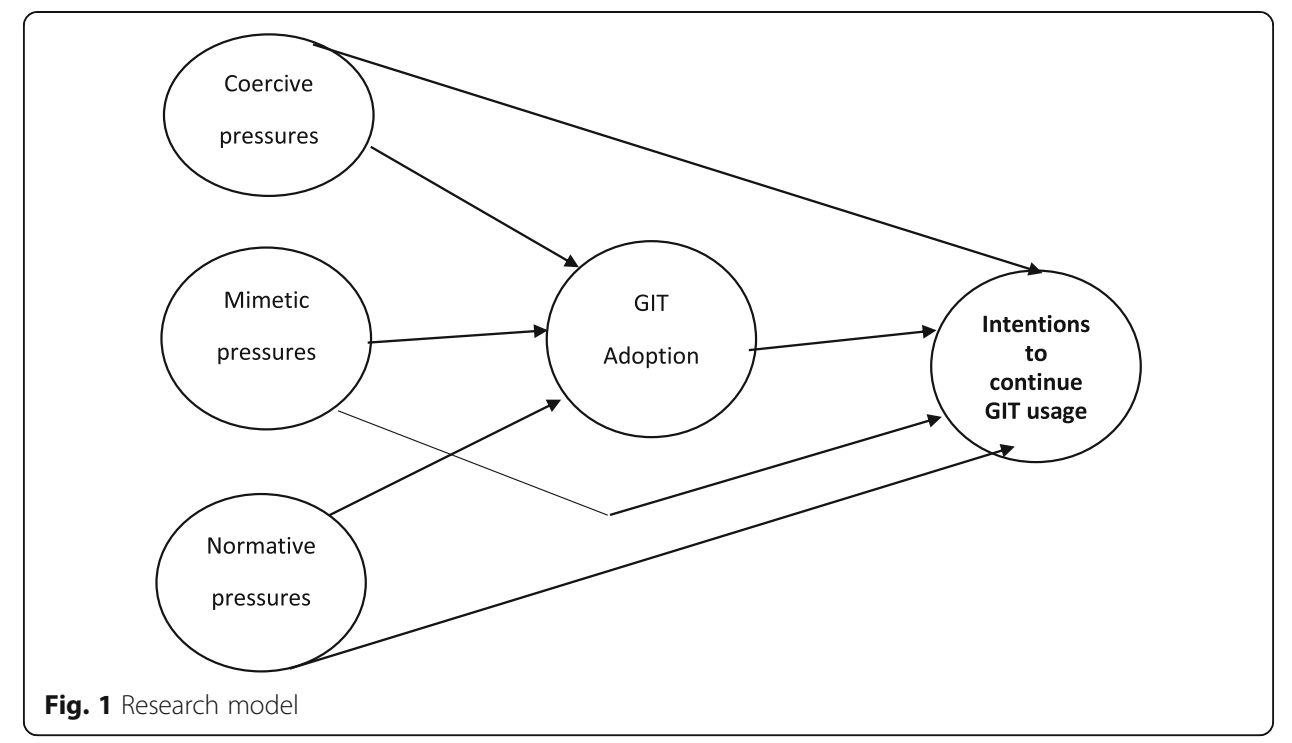

are considered independent variables that influence the manager's decision to adopt GIT. The independent and mediating variables in turn influence intentions to continue using GIT. The predicted model is depicted conceptually in Fig. 1. We present the details of five pressures in the following section.

\section{Coercive pressures}

SEs are Surrounded by institutions that impose on them, directly or indirectly, engaging in GIT practices. Otherwise, they would be Subjected to sanctions. Classical Institutional Theory that defined coercive pressures as the pressures which stem from institutions in a firm's environment which directly formulate rules that a firm need to comply with one of them. Based on the previous definition, institutions should be powerful enough to directly reward compliance or sanction noncompliance (DiMaggio and Powell 1983). In our case, these institutions that include likely resource dominant traders, customers, federal, and local agencies use their power to force SEs to involve in GIT practices, which, in turn, can directly impose constraints on them. According to Oliver 1991 coercive pressures mainly stems from the resource dependence perspective. Moreover, Pfeffer and Salancik (1978) also supported this view by stating that principal actors, who have control over certain rare resources, may demand other organizations that are dependent on the adoption of certain structures which serve their own interests. These dependent organizations often comply with such demands in order to secure their own survival. These pressures also stem from political influence and need for legitimacy (Coffey et al. 2013). Recently, the governments either, federal or local, have started making policies and regulations that play a significant role in forcing SEs to comply with the demands of environmental protection. These enterprises, in turn, could be getting benefits and avoid sanctions by responding to these requirements. When a resource-dominant organization, government agencies, and others perceive that SEs practices aren't going along with the societal goods adopting so GIT may be imposed on them. Consequently, the stronger SEs depend on organizations in the environment, and the fewer possibilities the firm that has to avoid negative sanctions, the 
stronger the coercive pressure, and the more will a firm be motivated to continue usage of GIT. Institutional theory researchers have shown that coercive pressures such as regulations are vital to create an environmental permit to adoption behavior (Lin and Ho 2016). Many studies have recommended that coercive pressures are an important predictor of GIT adoption (Kou, 2010; Lei and Ngai 2013; Gholami et al. 2013; Guo et al. 2016) Thus we hypothesize.

H1: Coercive pressures will be positively related to the adoption of GIT.

$\mathrm{H} 2$ : Coercive pressures will be positively related to the intentions to continue GIT usage.

\section{Mimetic pressures}

Organizations are enthused to adopt a given practice either because of the favorable results achieved by other adopters in the same context or by popularity of a practice. Organizations also mimic the behaviors of other organizations with whom they share important features. Mimetic isomorphism suggests that organizations will follow leading organizations, which have gained benefits from being the first movers in the industry (Deng and Ji 2015). This description applies to the adoption of GIT. After recognizing that other organizations in the environment have begun the practice of GIT and reap certain benefits. New organizations attempt to undertake similar steps of movement that of organizations. It becomes increasingly taken-for-granted so that many organizations may adopt such a practice without thinking (March 1981). It is defined as pressures that stem from behavioral uncertainty on how to solve a specific problem, perform a specific activity, or reach a specific goal (Krell et al. 2016). These kinds of pressures that are likely to arise when conditions are uncertain, making organization imitate the actions of other organizations. Coffey et al. (2013) claimed that organizations tend to imitate structure equivalent organizations which are perceived to be successful. Moreover, in order to avoid appearing different from many other organizations, they tried to join the institutional bandwagon (DiMaggio and Powell 1983). It does not preclude the need for the organization to obtain legitimacy in the social structure to keep up with other organizations. Krell et al. (2016) indicated that when the organizations have insufficient information to solve a problem, they observe other organizations in the environment due to successfully solved similar problems. Pieces of evidence of important mimetic pressures have shown in (Chen et al., 2012) study and were shown in (Coffey et al. 2013) study. Therefore, we suggest.

H3: Mimetic pressures will be positively related to the adoption of GIT.

H4: Mimetic pressures will be positively related to the intentions to continue GIT usage.

\section{Normative pressures}

Normative pressures are associated with professionalization, and it shapes organizational response (Deng and Ji 2015). This is clearly seen when worldwide decision makers are 
talking about the negative impact of IT and making a greater effort to reduce it. The normative pressures are manifested through dyadic inter-organizational channels of firm supplier and firm-customer relationship which enables organizations to learn about innovations along with their association benefits and cost (Burt, 1987). Much of these types of pressures are a result of increasing professionalization. This stems from concern about the level of education and the professional training that organizations received (Coffey et al. 2013). When environmental operation becomes the norm, green IT, as one big environmental step. Organizations would be adopted by facing great normative pressures which resulted from frequent contact with other suppliers, customers, or trade organizations (Deng and Ji 2015). Normative pressures are defined as the pressures that stem from norms which specified by institutions such as professional or industry associations (Krell et al. 2016). As such, more and more normative signals are emerging. Essentially, this types of pressures are different from coercive pressures in so far as institutions that exert normative pressures have no authority to directly enforce compliance and do not penalize noncompliance (Chen et al. 2011). Thus, normative pressures do not affect firms through coercion; rather, firms comply with the norms because decision makers identify themselves with particular industrial and professional institutions (Deng and Ji 2015). As a result, the decision makers believe that compliance with norms specified by the professional and industry institutions may be beneficial for their firm. SEs complies with GIT norms because key decision makers believed that compliance would help their firms to attract additional customers and showed their interested in protecting environment. Several previous studies have identified normative pressures as a predictor of GIT adoption (Kuo 2010; Lei and Ngai 2013). Based on the discussion above, the following hypothesis is proposed.

H5: Normative pressures will be positively related to the adoption of GIT.

H6: Normative pressures will be positively related to the intentions to continue GIT usage.

\section{GIT adoption}

Presumably, GIT adoption is a realistic way for organizations to tackle the current environmental problem. An important competitive advantage can be created by making the company distinguish itself from other SEs by means of GIT. At the same time, it also can be regarded as a means to improve the organizational image and economic performance (Gou et al., 2016). The adoption of GIT can be an example of organizational behavior that requested by institutions if the motive for adoption is to get accepted rather than to maximize organizations' efficiency. It is currently a nascent field and there is a lack of both theoretical and empirical research on the topic in Iraq. Since SEs under increasing institutional pressures to reduce the negative impact of IT on their environment, GIT adoption is a focus of managers of these firms. They follow GIT solutions such as lower carbon emissions and disposal of e-waste. However, given that an increasing number of SEs are experimenting with using GIT practices, there is an emerging need to understand GIT adoption as key factors for these practices flourishing. 
The adoption of GIT is reported to have additional motivational factors beyond those of standard IT adoption (Molla and Abareshi 2012). As such, these motivational factors may include economic benefits, regulation requirements, stakeholder obligations and ethical reasons which all need to be taken into account when exploring and analyzing factors that may influence the adoption of GIT (Khorasanizadeh et al. 2016). Even though, studies about organizations GIT adoption has recently proliferated in IT discipline, there seems to be considerable overlap between these factors, and there is difficulty in separating those. Furthermore, SEs managers may choose to adopt GIT either because of pressures or reap benefits. Seemingly, they are right because it is a confusing situation, and they definitely don't need to stay away. Many theoretical frameworks have been developed to study GIT adoption. From the perspective of Asadi and his colleagues in 2015, IT researchers have been emphasizing the effects of institutional pressures on organizations to GIT adoption.

As long as GIT is at early stages in the SEs, we would employ GIT adoption as mediate variable between institutional pressures and intentions to continuing usage of GIT. Based on the discussion above, the following hypothesis is formed.

H7: GIT adoption will be positively related to the intentions to continue GIT usage.

\section{Intentions to continue GIT usage}

IT continuance has emerged as a prominent area of IS/IT research. IT continuance refers to long-term or sustained use of IT by individual users over a period of time (Bhattacherjee and Lin 2015). A given IT cannot be considered successes if its usage is not sustained by users who are expected to have benefited from its usage (Bhattacharjee 2001). Adopting GIT a key question is what factors drive managers of SEs to continue GIT usage? In this context, several scientists highlighted the role of institutional pressures on GIT in influencing the acceptance and use of GIT practice (Chen et al. 2011; Akman and Mishra 2015). In line with earlier studies, we conceptualize GIT intention to continuing usage GIT as a dependent variable. While it was totally understandable to organizations working on the economic performance, then the managers start to realize that ignoring environmental performance something is strange. Diffusion and penetration of GIT practices throughout the organization give benefits such as reducing power consumption and carbon emissions, improving operation system performance and increasing interaction and collaboration (Deng and Ji 2015). However, in lieu of the emerging role of GIT and it benefits, it is imperative to understand SEs manager's intentions to continue GIT usage and clarify the development and flourish of GIT practices.

\section{Research methodology}

Sample and procedure

In light of the decline in the role of public sector companies that have dominated before 2003, SEs become the pillar that supports the Iraq economy. Over the last decade, SEs in Thi-Qar province dependence on IT has grown in both operationally and strategically to an unparalleled extent. Nowadays, few investigators would claim that IT represents a major source of environmental degradation. It has caused a major change in the climate reflecting in the high temperature, the scarcity of rain and increasing 
severity of dust storms in our country. The managers of SEs identify the importance of GIT practices. They are making an effort to carry out it in order to increase the competitiveness and to get legitimacy in their environment. At the same time, they have difficulties in adopting GIT due to a lack of pro-environment behavior. Parallel, but in a separate area of development of GIT, local and federal governments are creating more and more legislation regulating organizations. Hence, managers have increasingly faced both internal and external pressures to make GIT daily routine activities.

To address this situation, a survey questionnaire was developed to gain a better understanding of the institutional pressures which encourage managers of SEs to adopt GIT. Participants were selected based on prior researches confirmed that managers have knowledge of adoption motives (Krell et al. 2016). In addition, a study showed that the behavior of different groups in a society with different social-demographic characteristics may show totally different patterns (Molla et al. 2014). Moreover, this research considered the participation of the managers which had direct involvement and knowledge about the adoption of GIT practices within SEs. Thus, the participants with GIT adoption experience served as key informants during the data collection activities.

As long as GIT is a new concept and managers are assumed to possess a higher level of awareness and knowledge compared to other groups and were directly involved in their firm. GIT adoption decisions. Thereby, we expected to be competent to assess GIT adoption for the purpose of and this research. We obtained contact information of individuals identified as managers of SEs from Thi-Qar tax department and the Chamber of Commerce in Al-Nasiriya city. The participants were from different sectors, including building and construction, financial services, trade, and tourism. Table (1) present the summary of the respondent's industry.

The authors asked the participants in a training course on environmental challenges that held at the Federation of Businessmen to take part in the current study. They explained the meaning of GIT, clarified the goal of their research and provided them with instructions for completing the survey. After 2 weeks, questionnaires were sent via e-mail to the manager of the SEs in the targeted sample pool. A cover letter explained the purpose of the study, sought cooperation for participation and requested that the questionnaire should be completed by the manager of the company. Of 150 managers in the sample, 120 responses agreed to participate. After two reminders, from 120 responses we received (80\%), 21 responses were discarded from the analysis due to the vastly incomplete response rate $(66 \%)$. The high response rate may be happening because of the follow-up procedure for sending reminder letters and phone calls. Our research was carried out in Thi-Qar province during Full 2017.

Table 1 Respondents industry

\begin{tabular}{ll}
\hline Primary business category & Respondents \\
\hline Building and construction & 27 \\
Financial services & 25 \\
Information technology services & 17 \\
Publishing & 8 \\
Entertainment & 11 \\
Education & 6 \\
Tourism & 5 \\
\hline
\end{tabular}


Measures

Because of literature reviews showed that well-established measurement existed for all constructs, we used existing measurement to operationalize the constructs. The scales for the three institutional pressures namely coercive pressures, mimetic pressures, and normative pressures were adapted from prior studies. Coercive pressures from suppliers, government, and customers as a six-items reflective construct are adapted from (Teo et al. 2003; Liang et al. 2007) see (Additional file 1). The mimetic pressures were measured as a five-items reflective construct and normative pressures as a four-items reflective construct, both beings adapted from (Krell et al. 2016). GIT adoption was measured as a three-items reflective construct adapted from (Teo et al. 2003; Khorasanizadeh et al. 2016). The Dependent variable was measured by three-items borrowed from (Liang et al. 2007). All scale items were rephrased and minor adjustments to the wording of some items were done to ensure they capture the context of GIT adoption driven by institutional pressures in the English language version. Since the respondents were Arabic, back translation method was used to ensure the translation validity. In this study, the data were collected using a five-points Likert Scale $(5=$ very much, $4=$ much, 3 = moderate, $2=$ little, 1 = very little) for each item since it is the most widely used and effective tool for scaling responses in survey-type studies.

\section{Data analysis}

Partial Least Squares (PLS) is considered suitable for this study that owing to its good prediction capability and minimum demands in terms of sample size and residual distributions (Chin 1998). For this reason, the researchers employed it to test hypothesized relationships in this study Following (Anderson and Gerbing 1988). we adopted a two-steps approach to testing the models. First, we conducted a confirmatory factor analysis (CAF) to assess the measurement properties of reflective latent constructs. Second, we performed path analysis to test research hypotheses.

\section{Result and analysis}

In accordance with prior studies, we assessed the validity and reliability of reflective items and constructs by examining the loading of items on their respective latent variable. Scale reliability and validity were assessed using confirmatory factor analysis to extract the factors. (CFA). Principal component analysis and Maximum Likelihood method was used. CFA was performed in this study using PLS approach. The results confirmed the existence of five factors with eigenvalues greater than 1.0 that accounted for $84 \%$ of the total variance. The criteria used to identify and interpret the factors where each item should load 0.50 or greater on one factor and 0.35 or below on the other factors (Igbaria et al., 1995). Table 2 shows that factor one (with six items) measures coercive pressure. Similarly, factor two (with five items) and factor three (with four items) measure mimetic pressures and normative pressures respectively. Also, factor four (with three items) measure GIT adoption, factor five (with three items) measures intentions. These results, therefore, approve that all of these constructs are unidimensional and factorially distinct and all items used to operationalize a particular construct loaded onto a single factor. As represented in Table 2. Five factors were identified, all items loaded heavily and significantly $(P<0.05)$ on their respective constructs; 
Table 2 Factor Loadings

\begin{tabular}{|c|c|c|c|c|c|c|}
\hline Items & Coercive & Mimetic & Normative & GIT adoption & Intention & communalities \\
\hline COP1 & 0.85 & 0.22 & 0.11 & 0.10 & 0.17 & 0.81 \\
\hline COP2 & 0.89 & 0.14 & 0.11 & 0.13 & 0.26 & 0.84 \\
\hline COP3 & 0.84 & 0.11 & 0.13 & 0.14 & 0.18 & 0.77 \\
\hline COP4 & 0.86 & 0.08 & 0.18 & 0.09 & 0.14 & 0.81 \\
\hline COP5 & 0.82 & 0.12 & 0.13 & 0.08 & 0.13 & 0.72 \\
\hline COP6 & 0.87 & 0.10 & 0.15 & 0.11 & 0.16 & 0.82 \\
\hline MIP1 & 0.11 & 0.81 & 0.09 & 0.09 & 0.14 & 0.70 \\
\hline MIP2 & 0.10 & 0.84 & 0.10 & 0.08 & 0.07 & 0.75 \\
\hline MIP3 & 0.14 & 0.93 & 0.08 & 0.16 & 0.06 & 0.86 \\
\hline MIP4 & 0.16 & 0.83 & 0.16 & 0.24 & 0.11 & 0.75 \\
\hline MIP5 & 0.19 & 0.79 & 0.09 & 0.09 & 0.14 & 0.73 \\
\hline NOP1 & 0.18 & 0.10 & 0.82 & 0.08 & 0.16 & 0.74 \\
\hline NOP2 & 0.21 & 0.12 & 0.81 & 0.07 & 0.08 & 0.72 \\
\hline NOP3 & 0.22 & 0.08 & 0.84 & 0.08 & 0.08 & 0.77 \\
\hline NOP4 & 0.19 & 0.09 & 0.90 & 0.08 & 0.12 & 0.81 \\
\hline GITA1 & 0.18 & 0.14 & 0.09 & 0.88 & 0.13 & 0.84 \\
\hline GITA2 & 0.21 & 0.11 & 0.11 & 0.87 & 0.11 & 0.83 \\
\hline GITA3 & 0.22 & 0.12 & 0.13 & 0.86 & 0.10 & 0.81 \\
\hline GITI1 & 0.09 & 0.10 & 0.12 & 0.14 & 0.82 & 0.72 \\
\hline GITI2 & 0.19 & 0.12 & 0.11 & 0.16 & 0.92 & 0.91 \\
\hline GITI3 & 0.13 & 0.09 & 0.10 & 0.18 & 0.84 & 0.76 \\
\hline Eigenvalue & 4.69 & 3.66 & 2.97 & 2.58 & 2.56 & 16.46 \\
\hline Explained variance\% & 0.28 & 0.22 & 0.18 & 0.16 & 0.16 & \\
\hline Cumulative \%of explained variance & 0.28 & 0.50 & 0.68 & 0.84 & 0.100 & \\
\hline
\end{tabular}

COP Coercive pressure, MIP Mimetic pressure, NOP Normative pressure, GITA GIT adoption, GITC intentions to continue GIT usage

the results are indicative of individual item reliability. Consistent with prior studies, we assessed the reliability of our scales using composite reliability (CR) (Werts et al. 1974). $\mathrm{CR}$ is preferred over Cronbach's a because it offers a better estimate of variance shared by the respected indicators and because it is using item loadings which obtained within the nomological network (Hair et al. 2006). Furthermore, it is perceived as a stronger reliability assessment when compared to Cronbach's and is considered a more conservative test of reliability (Garver and Mentzer 1999). CR scores for all scales (CR ranged from 0.79 to 0.88) exceed the minimum threshold level of 0.70 (Kilne 1998). Indicating the reliability of the scales used in this study. For discriminant validity, scholars have suggested that the square root of the average variance extracted (AVE) of the constructs should exceed the inter-correlations among the constructs in the mode (Fornell and Larcker 1981). The correlation matrix presented in Table 2 indicates that the square roots of AVE on the diagonal are greater than the corresponding off-diagonal inter-construct correlations. Thus, the discriminant validity of all factors were supported. Self-reported data may be affected by common method variance (Hulland 1999). Therefore, common method bias (CMB) problems may have occurred. To test CMB in our research, we conducted Harman's one-factor test (Harman 1967) through performing an exploratory factor analysis with all manifest items (Podsakoff et al. 2003). 
The results of the analysis showed that all produced factors had eigenvalues greater than 1 , and the "largest" factor accounted for only $28 \%$ of the total variance. No single factor explained the majority of the variance. Thus, common method bias does not seem to be of concern. In addition, the matrix of correlations (see Table 3) does not indicate any highly correlated factors (the highest correlation is $<49$ ), whereas evidence of common method bias would have resulted in extremely high correlations $(r>0.90)$. In summary, our results showed that neither case exists; therefore, our data do not indicate evidence of substantial common method bias (Chin et al. 2003). The convergent validity of the constructs, which tested whether individual indicators are indeed measuring the constructs that are purported to the measure, was determined by calculating the average variance extracted (AVE) and by examining the indicator loadings in line with the perspective (Chin et al. 2003).

AVEs as we see in Table 3, the diagonal elements (square root of the AVE for each construct) is greater than the off-diagonal elements, indicating that each construct shared more variance with it measures greater than with other constructs (Bagozzi et al. 1991). Furthermore, loadings were above the recommended threshold of 0.6 (Chin 1998). Thus, supporting convergent validity.

The results are presented in Tables 2 and 3. The discriminant validity, which assesses whether individual indicators can adequately distinguish among different constructs, was determined by examining the square root of AVEs in relation to the inter-construct correlations (Garver and Mentzer 1999). Based on Table 3, none of the inter-construct correlations were larger than the square root of the AVEs. Hence, we conclude that an acceptable level of discriminant validity was achieved.

\section{Structural model}

The test of the structural model consisted of path coefficients $(\beta)$ and the coefficients of determination $\left(R^{2}\right)$. Whereas path coefficients confirmed the strength of the relationships between dependent and independent constructs, the $R^{2}$ values indicated the amount of variance that explained independent constructs, represented the predictive power of the model, and were interpreted in the same way as a multiple regression.

We took several steps to check for possible violations of the assumptions underlying path analyses. First, an examination of CR indicated satisfactory levels of internal consistency reliability among the multi-item scales. Second, we checked the matrix of correlation in Table 3 for evidence of multi-collinearity among the independent variables. Since all the correlations are below 0.50, multi-collinearity is not a problem (Billings and Wroten 1978) and factor analysis confirmed the existence of five distinct measures. Third, we also checked

Table 3 Correlates for research constructs $(N=99)$

\begin{tabular}{llllll}
\hline & Coercive & Mimetic & Normative & GIT adoption & Intention \\
\hline Coercive & 0.85 & & & & \\
Mimetic & 0.23 & 0.84 & & & \\
Normative & 0.27 & 0.25 & 0.84 & 0.87 & \\
GIT adoption & 0.31 & 0.34 & 0.30 & 0.49 & 0.86 \\
Intention & 0.43 & 0.42 & 0.46 & \\
\hline
\end{tabular}

Pearson correlations are given below the diagonal, the absolute value of correlations $\geq .19$ are significant at 0.05 level or better Diagonal elements represent AVE value 
variance inflation factor values for all the constructs, and the results were less than 2.2 which was below the rule-of-thumb cut-off of 10 (Neter et al. 1990), suggesting that multicollinearity is not a serious issue in this study. Furthermore, multi-collinearity is examined by using squared correlations. The squared correlations between constructs in the correlation matrix Table 3 are not above 0.8 , suggesting that the multi-collinearity does not cause a serious problem (Zhou et al. 2014).

To obtain the path coefficients required to test the research model, iterations of multiple regressions were performed. First, we regressed GIT adoption on institutional pressures. In a similar manner, GIT continuance intention was regressed on the exogenous variable. The path coefficients from the three components of institutional pressures (coercive pressure, normative influence and mimicry pressure) to GIT were significant. Also, they had significant effects on continuance intention. Likewise, the path of coefficient from GIT adoption to continuance intention was significant, indicating that all the hypotheses were supported. Examination of the data in Table 3 shows that all the direct paths tested in the model.

H1 stated that coercive pressures positively influence the GIT adoption. Consistent with our expectations, this hypothesis was supported $(\beta=0.40, T=2.21, p<0.5)$. Values of the path from mimetic pressures to GIT adoption $(\beta=0.37$., $T=2.16, p<0.05)$ this lead to acceptance of H3. Similarly, H5 hypothesis stated that normative pressures positively influence on GIT adoption was supported $(\beta=0.39, T=2.31, p<0.05)$, also $\mathrm{H} 2$ hypothesis $(\beta=0.43, T=2.39, p<0.05)$ was supported. H7 stated that GIT adoption positively influences continuance intention. This hypothesis was supported $(\beta=0.44$, $T=2.45, p<0.05)$. As stated in $\mathrm{H} 4$, the mimetic approach has a positive effect on continuance intention. This hypothesis was also supported $(\beta=0.38, T=2.71, p<0.05)$. Finally, $\mathrm{H} 6$ stated that normative positively affects continuance intention. This hypothesis was also supported $(\beta=0.42, T=3.42, p<0.05)$. Commonalities are describing as the proportion of each variable's variance that can be explained by the factors, and the high value of the communalities reflected the ability of this test to measure the capacity in which set for. It has achieved all "items" ratio exceeded (0.70), a high percentage.

Comparison of the estimated correlations as represented by the sum of the direct and indirect effects (i.e., total effects) with the original correlations between the independent variables and the dependent variables provides further evidence of the "goodness of fit" of the model. With the criterion that the absolute difference between the reproduced (i.e., total effects) and original correlations does not exceed 0.10 (Namboodiri et al. 1975), the data shows that the model duplication all the correlations for GIT adoption and intention continuance. The path coefficients and explained variances of the structural model are shown in Table 4. The PLS result of the structural model, including the standardized path coefficients, significance, and variance explained $\left(R^{2}\right)$ are shown in this figure. The model explained $79 \%$ of the variance in continuance intention, and $37 \%$ of the variance in GIT adoption.

\section{Discussion}

The primary objective of this research was to empirically examine the effect of institutions pressures on the intentions of managers of SEs in Thi-Qar province to continue using GIT. Three research questions drove this study: (Akman and Mishra 2015) Do institutional pressures (coercive, mimetic, and normative) influence the intentions of 
Table 4 Direct, indirect and total effects of institutional pressures on GIT adoption and intentions to continuing usage GIT

\begin{tabular}{|c|c|c|c|c|c|}
\hline \multirow[t]{2}{*}{ Variable } & \multicolumn{2}{|l|}{ GIT adoption } & \multicolumn{3}{|c|}{ intentions to continue usage of GIT } \\
\hline & Direct effect & $r$ & Direct effect & Indirect effect & $r$ \\
\hline Coercive & 0.40 & 0.31 & 0.42 & 0.09 & 0.43 \\
\hline Mimetic & 0.37 & 0.34 & 0.38 & 0.08 & 0.42 \\
\hline Normative & 0.39 & 0.30 & 0.43 & 0.07 & 0.46 \\
\hline GIT adoption & & & 0.44 & 0.09 & 0.49 \\
\hline
\end{tabular}

managers SEs to the continuation usage GIT? (Alzaidy 2018) Are their effects differ? (Anderson and Gerbing 1988) What is the role of GIT adoption? The current research addressed these questions through the development and empirical testing of a theoretical model.

We first discuss the main findings and then presents the theoretical contributions and practical implications in more detail. Our analysis provides strong support for the main effects of normative, coercive and mimetic pressures respectively. Based on this result, we can say that we found support for the hypotheses that normative coercive, and mimetic pressures respectively decide to adopt GIT. The results demonstrate that these three pressures have a positive influence on how managers of SEs adopted GIT. During an interview with a couple of managers, they stated that their firms are successfully enjoying local reputation resulting from the adoption of GIT. Nevertheless, they are currently facing pressures from government, suppliers, and customers that force them to put GIT on their agenda. Consequently, coercive pressures may motivate subjects to adopt GIT. In the same context, regulations are a significant source of coercive pressures compared with suppliers and customers' pressures based on the high proportion of the research sample agreement. on the items relevant. This reflects the effectiveness of government efforts in guiding green behaviors across organizations, specifically when such behaviors have an organization-wide influence (Zezder, 2017). These findings are consistent with (Akman and Mishra 2015) finding, where government policies that encourage GIT practices during IT lifecycle were among the most important reason for adopting GIT practices. Chen et al. (2011) found that coercive pressures in the form of regulations had the most impact in the areas of pollution prevention and sustainable development compared with mimetic pressure. In the perspective of (Krell et al., 2016), the government in a developing country is playing an important role in drawing the environmental constraints and GIT adoption. In terms of this study, we attribute this result in the efforts of the federal government and the local administration to impose regulations to control environmental activities of small enterprises and diffuse pro-environmental practices, especially, as most managers of SEs try to build on their economic goals, and achieve their environmental goals, and it is a good idea to balance these goals, but they completely forget this. This suggested that the adoption of GIT by managers of SEs due to external powers.

Unlike study of (Chen et al. 2011), which excluded normative pressure, the results of our study indicate that normative pressures had strongest effect of GIT adoption. In other words, this suggests that the decision-makers in the surveyed companies have 
put in their minds the benefits that can be obtained when they Adopt GIT. Likewise, they want to strengthen their relationships with other firms and professional associations already had practiced GIT to gain benefits. According to (Teo et al. 2003) a focal organization with direct or indirect ties to other organizations that have adopted an innovation is able to learn about that innovation and its associated benefits and costs and is expected would influenced to act similarly. The difference also found the support for our hypothesis that mimetic pressures that have a positive effect on GIT adopt. Norms advocated by business and professional circles played a primary role in organizational decision makers' attitudes to adopt GIT because these business and professional associations provide an arena in which highly visible organizations supportive GIT adoption. The efforts are given strong recognition and important influence (DiMaggio and Powell 1983).

Mimetic pressures were significant when decision makers perceived adoption GIT useful. Teo et al. (2003) suggested that when technologies are poorly understood, mimetic pressures would likely strength, unlike coercive and normative pressures. SEs decision makers may base their own decisions about adoption GIT on its pattern of use and its effects on similar others to economize on search and experimentation costs to reduce associated risk.

Krell et al. (2016) observed that imitating other organizations from institutional environment, which are similar to the firm, appears to be a positive tactic to enrich the firm's learning experience. Lin and Ho (2016) demonstrated that decision maker would rather imitate another organization's IT choice than following recommendations produced internally; that is, a decision maker would discard results from an internal evaluation of different technology alternatives in favor of copying another organization's choice. This result is in line with the finding of (Akman and Mishra 2015) who show there are a few firms that leverage the investment in GIT as potential sources of competitive advantage which motive other to copy it. Along the same lines (Coffey et al. 2013) organizations were unlikely to be influenced by the number of other organizations adopting Green IT practices, but if they observed positive outcomes in other organizations as a result of adopting those practices, then they were more likely to adopt such practices themselves. A plausible explanation for this observation may be based on another point because GIT is still an emerging phenomenon, most SEs are using it to improve their ability to effectively execute operational processes. Instead, a couple of them have recognized that GIT enables a fundamental shift in the way. IT capabilities are delivered and it can be used to improve operational performance and combat environmental issues. Consequently, imitating the successful one is not uncommon. Additionally, there is a realization that GIT has played a crucial role in the race towards getting market share. Extant research suggests that effective and efficient use of GIT by organizations is dependent on the level of market dynamism within the external environment. In the light of the above arguments, the institutional pressures effect widely in adopting SEs GIT. Thus, the first equation of this research was answered. Existing research has shown that adopt GIT should not be regarded as full compliance with environmental protection rules which may be imposed by organizations in the organizational field; instead, it should be used as a force to improve performance, build and strength their market competitiveness. For this reason, continued dependence on GIT becomes a strategic option which is 
also affected by institutional pressures. These findings indicate that organizations are embedded in institutional networks and call for greater attention to be directed after understanding the importance of institutional pressures when investigating GIT adoption.

The findings of this study support the proposed (Hypothesis 2, 4, 6) that is a positive relationship between institutional pressure and intentions continuing usage GIT. These results are consistented with results of prior studies (Molla et al. 2014; Alzaidy 2018). The data shows that institutional pressures for environmental sustainability support GIT practices of SEs for the purpose of reducing overall emissions and e-waste. In detail, the findings lead to the conclusion that pressures from customers and competitors for GIT have a positive effect on the intentions to continuing usage GIT practices by ESs as a mean to decrease its negative environmental. This is reasonable because growing positive community awareness of GIT practices forces all organizations to implement GIT that is environmentally intact. Contrary to expectations, whereas the result showed that normative pressures has great impact on GIT adoption, turning out that coercive pressures were having most influences into Intentions managers of SEs in Thi-Qar province to continuing usage GIT. That SEs is under growing pressure from competitors, customers, regulators, and community groups to implement GIT practices. Among the social indicators, normative pressur exhibit the strongest influence on organizational predisposition toward GIT. Our finding confirmed that the influence of customers, suppliers, and government actions in encouraging managers of SEs on intentions to continuing usage GIT is the main impact. In the same vein, normative and mimicry pressures effected on the intentions to continuing usage GIT. This means that if other organizations in the industry are using their GIT standing as a responsible business behavior to gain market share, this behavior would be accepted and would be become a common daily activity. From the other side when GIT can reduce costs or increase revenue, the organization will be more receptive to such initiatives. This trend might be attributed as described in (Molla et al. 2014). Molla and his tem observed that in pressures of market forces become a relevant mimetic motivation when early adopters' demonstrate satisfactory outcome out of their green practice. We find that GIT adopted has a significant influence on the intention to continue usage of GIT. This result provides strong support for adoption GIT as a predictor of intentions to continuing usage GIT and as mediating variable between them. When there is a shift or major change in the SEs context, the shift can dramatically reshape the industry structure and define the context of the competitive strategies used by small enterprises to build new sources of competitive advantage. As a result of operating in the environment needs to pursue and address environmental degradation, SEs have to assiduously persevere in the practice green IT. Another explanation for the adoption of GIT appearing to be significant in SEs environments could be the tendency of the organizations in such an environment to exhibit environmental culture and commitment of pro-environment behavior in the future after understanding the importance of it. These results provide strong support for adoption GIT as predictors of intentions to continuing usage for Fig. 2 illustrates the network of relationships among the variables for which significant path coefficients were found. Standardized path coefficients $(\beta)$ are reported; all are significant at 0.05 level or better. 


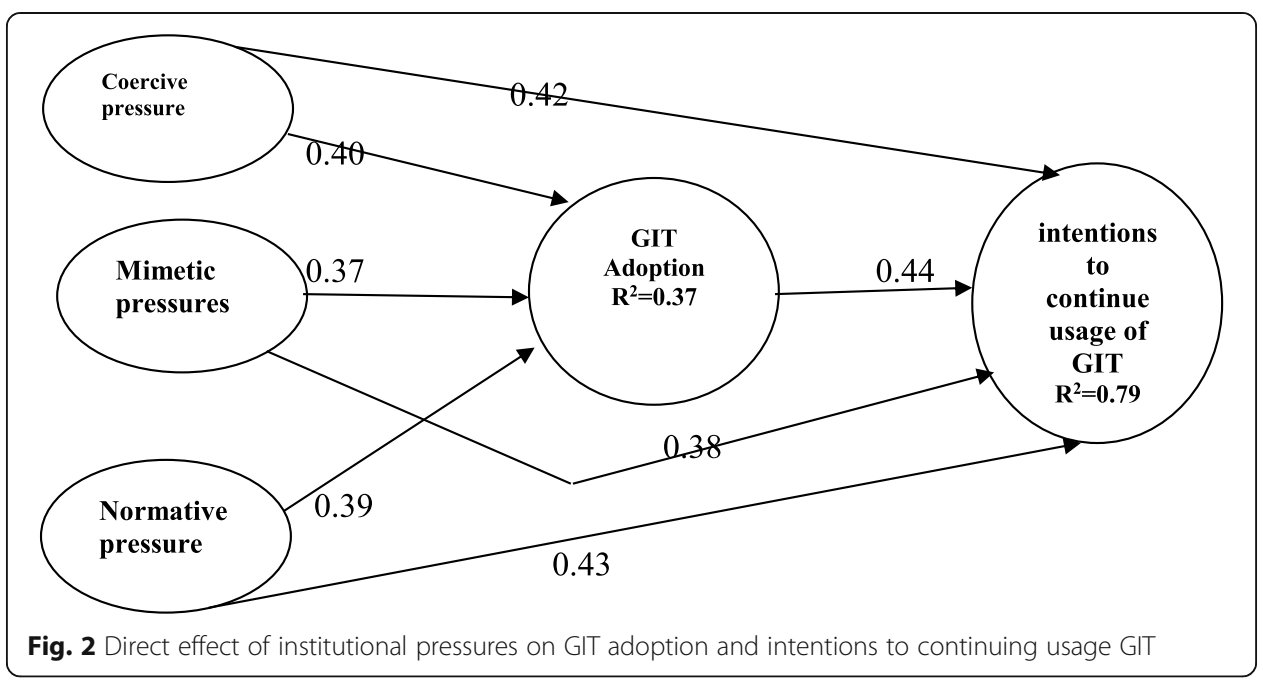

\section{Conclusion, limitation and future work}

The effect of institutional pressures on adoption and intentions to continuing usage GIT in SEs in Thi-Qar province has not been investigated to date. The results from this research will contribute towards understanding what pressures that influence this adoption. This will enable future movements towards implementing GIT solution in SEs in our country, thereby promoting the sustained practice and usage of IT infrastructure and support. As a result of small sample size, the results of this research should be viewed as an explorative study into some the perceptions of managers on the pressures driving the adoption of GIT in SEs in Thi-Qar province and intentions to continuing usage GIT. In spite of the small sample size, strong correlations between factors were shown.

The findings of the present study contribute to a better theoretical understanding of the factors that promote GIT adopt and continuance intention. It should be noted, however, that the model variables explained $37 \%$ of the variance on adoption and $79 \%$ of the variance of intentions to continuing usage GIT. A large percentage of the adoption and intentions to continuing usage GIT variance remains unexplained suggestion needed for additional research incorporating potential unmeasured variables in the current study.

Despite of the contributions of this study to literature, it is also not free from limitations. First, the study explores GIT adoption in SEs within Iraqi context. These enterprises have different characteristics, IT infrastructure setup, and commitment to environment. Second, the key limitation of the current research in the small sample size. Therefore, a study involved other organizations with different GIT adoption and environmental perspective which would tell us additional insights on the current state of GIT adoption practices in SEs in the Iraq and motivation to adopt it.

These findings need to be confirmed through further researches with a larger sample size. Additionally, it will be interesting to study the influence of institutional pressures on public organizations in Iraq to see which one is more effective. 


\section{Additional file}

Additional file 1: Survey Instrument: all the participants marked number to indicate the extent to which agree with the following statements. (DOC $72 \mathrm{~kb}$ )

\section{Acknowledgements}

The author would like to thank all the mangers of small enterprises at Thi-Qar province in Iraq. The author also would like to thank Dr. Sabah Enayah for language assistant and for typing.

\section{Funding}

No fund source all cost was depending on author private payments.

\section{Availability of data and materials}

The datasets generated during and/or analyzed during the current study are available from the corresponding author on reasonable request.

\section{Authors' contributions}

ADJ is the correspond author for all the works. Both authors read and approved the final manuscript.

\section{Competing interests}

The authors declare that they have no competing interests.

\section{Publisher's Note}

Springer Nature remains neutral with regard to jurisdictional claims in published maps and institutional affiliations.

\section{Author details}

${ }^{1}$ Department of Business Administration, College of Economic and Administration, The University of Thi-Qar, Nasiriyah, Iraq. ${ }^{2}$ Department of Biology, College of Science, The University of Thi-Qar, Nasiriyah, Iraq.

Received: 10 June 2018 Accepted: 11 December 2018

Published online: 24 January 2019

\section{References}

Akman I, Mishra A (2015) Sector diversity in green information technology practices: technology acceptance model perspective. Comput Hum Behav 49:477-486

Alzaidy AAD (2018) Studying the effect of institutional pressures on intention the managers of small enterprise at Thi-Qar province to adopt environmental disposal of electronic waste. Manag Stud J 30:1-25

Anderson J, Gerbing D (1988) Structural equation modeling in practice: a review and recommended two-step approach. Psychol Bull 103(3):411-423

Ardito L, Morisio M (2014) Green IT-available data and guidelines for reducing energy consumption in IT systems. Sustain Comput Inform Syst 4(1):24-32

Bagozzi P, Yi Y, Phillips L (1991) Assessing construct validity in Organizationa research. Adm Sci Q 36(3):421-458

Bhattacharjee A (2001) Understanding information systems continuance: an expectation-confirmation model. MIS Q 25(3): $351-370$

Bhattacherjee A, Lin C (2015) A unified model of IT continuance :three complementary perspectives and crossover of technology. Eur J Inf Syst 24(4):364-373

Billings R, Wroten S (1978) Use of path analysis industrial / organizational psychology: criticisms and suggestions. J Appl Psychol 63(6):677-688

Bohas A, Poussing N (2016) An empirical exploration of the role of strategic and responsive corporate social responsibility in the adoption of different Green IT

Burt R, (1987) Social contagion and innovation: cohesion versus structural equivalence. Am J Sociol 92(6):1287-1335

Cai S, Chen X, Bose I (2013) Exploring the role of IT for environmental sustainability in China: an empirical analysis. Int J Prod Econ 146:491-500

Chen A, Watson R, Boudreau M, Karahanna E (2011) An institutional perspective on the adoption of green IS and IT. Australas $J$ Inf Syst 17(1):5-27

Chen A, Watson T, Boudreau M, Karahanna E (2009) Organizational adoption of Green IS \& IT: an institutional perspective. Proceedings of the 30th international conference on information systems (ICIS), Phoenix December

Chen AJ, Boudreau MC, Watson RT (2008) Information systems and ecological sustainability. J Syst Inf Technol 10(3):186-201.

Chin W (1998) The partial least square approach to structural equation modeling. In: Marcoulides GA (ed) Methods for Business Research. Lawrence Erlbaum Associates, Mahwah, pp 295-336

Chin W, Marcolin B, Newsted P (2003) A Partial Least Squares Latent Variable Modeling Approach for Measuring Interaction Effects: Result Monte Carlo simulation study and an electronic-mail emotion from adoption study. Inf Syst Res 14(2):189-217

Coffey P, Tate M, Toland J (2013) Small business in a small country: attitudes to "Green" IT. Inf Syst Front 15(5):761-778

Deng Q, Ji S (2015) Organizational green IT adoption: concept and evidence. Sustainability 17:16737-16755

DiMaggio J, Powell W (1983) The iron cage revisited: institutional isomorphism and collective rationality in organizational fields. Am Sociol Rev 48(2):147-160

Fornell C, Larcker F (1981) Evaluating structural equation models with unobservable variables and measurement error. J Mark Res 18(1):39-50 
Gartner (2018) Gartner Says Global it Spending to Reach \$3.7 Trillion in 2018 [WWW Document]. URL. https://www.gartner. $\mathrm{com} /$ newsroom/id/3845563. Access 8 Feb 2018

Garver M, Mentzer J (1999) Logistics research methods: employing structural equation modeling to test for construct validity. J Bus Logist 20(1):33-57

Gholami A, Sulaiman T, Ramayah T, Molla A (2013) Senior managers' perception on green information systems (IS) adoption and environmental performance: results from a field survey. Inf Manag 50(7):431-438

Guo J, Liu Z, Liu Y (2016) Key success factors for the launch of government social media platform: Identifying the formation mechanism of continuance intention. Comput Hum Behav 55(2):750-763

Hair JF, Anderson RE, Tatham RL, Black WC (2006) Multivariate Data Analysis. Prentice-Hall, Upper Saddle River

Hardin-Ramanan S, Chang V, Issa T (2018) A green information technology governance model for large Mauritian companies. $J$ Clean Prod 198:488-497

Harman H (1967) Modern factor analysis. University of Chicago Press, Chicago

Hernandez A (2017) Green IT adoption practices in education sector: a developing country perspective. Int J Sociotechnol Knowl Dev 9(3):1-15

Hernandez A, Ona SE (2016) Green IT adoption: lessons from the Philippines business process outsourcing industry. Int I Soc Ecol Sustain Dev 7(1):1-34

Hulland J (1999) Use of partial least squares (PLS) in strategic management research: a review of four recent studies. Strateg Manag J 20(2):195-204

Igbaria M, livari J, Maragahh H (1995) Why do individuals use computer technology? A Finnish case study. Inf Manag No. 29, PP. 227-338.

Jenkin T, Webster J, McShane L (2011) Agenda for 'Green' information technology and systems research. Inf Organ 21(1):17-40

Khorasanizadeh H, Honarpour A, Sang-Ah Park M, Parkkinen J, Parthiban R (2016) Adoption factors of cleaner production technology in a developing country: energy efficient lighting in Malaysia. J Clean Prod 131:97-106

Kilne R (1998) Principles and practice of structural equation modeling. Guilford Press, New York

Krell K, Matook S, Rohde F (2016) The impact of legitimacy-based motives on IS adoption success: an institutional theory perspective. Inf Manag 53(6):683-697

Kuo BN (2010) Organizational Green IT: It Seems the Bottom Line Rules. In: Proceedings of the 16th Americas Conference on Information Systems, Lima, Peru, 12-15

Lei C, Ngai E (2013) Green information technologies adoption: a managerial perspective. In: PACIS Proceeding Paper 274

Liang H, Saraf N, Hu Q, Xue Y (2007) Assimilation of Enterprise systems: the effect of institutional pressures and the mediating role of top management. MIS Q 31:59-87

Lin L, Ho L (2016) Institutional pressures and environmental performance in the global automotive industry: the mediating role of organizational ambidexterity, Long Range Planning 49(6):746-755

Lin R.J, (2013) Using fuzzy DEMATEL to evaluate the green supply chain management practices. J Clean Prod 40:32-39.

March J (1981) Decisions in organizations and theories of choice. In: Van de Ven AH, Joyce WF (eds) Perspectives on organization design and behavior. Wiley, NY, pp 205-244

Molla A, Abareshi A (2012) Organization green motivation for information technology: empirical study the journal of computer information systems. Spring 52(3):92-102

Molla A, Abareshi A, Cooper V (2014) Green IT beliefs and pro-environmental IT practices among IT professionals. Inf Technol People 27(2):129-154

Molla A, Pittayachawan S, Corbitt B (2009) Green IT diffusion: an international comparison, Working paper. School of Business Information Technology, RMIT University, Melbourne

Moola A, Cooper V, Corbitt B, Deng H, Pittayachawan S, Yeoh S (2008) E-readiness to g-readiness: developing a green information technology readiness framework. Proceedings of the 19th Australasian Conference on Information Systems, Christchurch, pp 669-678

Murugesan S (2008) Harnessing Green IT: principles and practices. IT Prof IEEE Comput Soc 10(1):24-33

Murugesan S, Gangadharan GR, (Eds.) (2012). Harnessing green IT: Principles and practices. Chichester: Wiley

Namboodiri N, Carter L, Blalock H (1975) Applied Multivariate Analysis and Experimental Design. McGrawHill, New York Neter J, Wasserman W, Kutner MH (1990) Applied linear statistical models. Irwin, Homewood

Nishant R, Teo T, Goh M (2013) Understanding the environmental impact of sustainable IT: an empirical examination

Oliver C (1991) Strategic responses to institutional processes. Acad Manag Rev 16(1):145-179

Pfeffer J, Salancik G (1978) The external control of organizations: a resource dependence perspective. Harper \& Row, New York

Podsakoff M, MacKenzie B, Jeong-Yeon L, Podsakoff P (2003) Common method biases in behavioral research: critical review of the literature and recommended remedies. J Appl Psychol 88(5):879-903

Sarkis J, Pilar G, Diaz B (2010) Stakeholder pressure and the adoption of environment practices :the mediating effect of the training. J Oper Manag 28:163-176

Teo H, Wei K, Benbasat I (2003) Predicting intention to adopt interorganizational linkages: an institutional perspective. MIS Q 27(1):19-49

Thomson S, van Belle J (2015) Antecedents of Green IT Adoption in South African Higher Education Institutions. Electron J Inf Syst Eval 18(2):172-186

Tingling P, Parent M (2002) Mimetic isomorphism and technology evaluation: does imitation transcend judgment? J Assoc Inf Syst 3(1):113-143

Watson R, Boudreau M, Chen A (2010) Information systems and environmentally sustainable development: energy informatics and new directions for the IS community. MIS Q 34(1):23-38

Werts E, Linn L, Joreskog G (1974) Intraclass reliability estimates - testing structural assumptions. Educ Psychol Meas 34(1):25-33

Xia D, Chen B, Zheng Z (2014) Relationships among circumstance pressure, green technology selection and firm performance. J Clean Prod 106:487-496

Yang Z, Sun J, Zhang Y, Wang Y (2018) Peas and carrots just because they are green? Operational fit between green supply chain management and green information system. Inf Syst Front 20:627-645

Zhou Z, Jin X-L, Fang Y (2014) Moderating role of gender in the relationships between perceived benefits and satisfaction in social virtual world continuance Decision Support Systems, 65,69-79 